Type of the Paper (Article.)

\title{
Morphological Study of Zinc-Oxide Nanorods Grown by Hot Water Treatment Suitable for Solar Cells Conversion Efficiency Enhancement
}

\author{
Mohammad Khairul Basher 1", S. M. Shah Riyadh ${ }^{2}$, Md. Khalid Hossain ${ }^{1}$, Mahmudul Hassan ${ }^{3}$, \\ Md. Abdur Rafiq Akand ${ }^{1}$, S. M. Amir Al-Zumahi', Md. Abdul Matin ${ }^{4}$, Mohammad Nur-E- \\ Alam $^{5 *}$, Narottam Das ${ }^{6,7}$ \\ ${ }^{1}$ Institute of Electronics, Bangladesh Atomic Energy Commission, Dhaka-1349, Bangladesh, e-mail: \\ khairulcu@gmail.com (M. K.B.), khalid.baec@gmail.com (M. K. H.), rafiq29nov@yahoo.com (M. A. R. A.), \\ amirzumahi@gmail.com (S. M. A. Al- Z.) \\ ${ }^{2}$ Department of Physics and Astronomy, University of Louisville, Louisville, KY, 40292, USA, e-mail: \\ riyadh.sust@gmail.com (S. M. S. R.) \\ ${ }^{3}$ Institute of Energy, University of Dhaka-1000, Bangladesh, e-mail: mahmudphy1012017@gmail.com (M.H) \\ ${ }^{4}$ Glass and Ceramic Engineering (GCE), Bangladesh University of Engineering and Technology (BUET), \\ Dhaka-1000, e-mail: matin.md.a@gmail.com (M. A. M.) \\ ${ }^{5}$ Electron Science Research Institute, Edith Cowan University, WA, 6027, Australia, e-mail: m.nur-e- \\ alam@ecu.edu.au (M.N.-E-A.) \\ ${ }^{6}$ School of Engineering and Technology, Central Queensland University Australia, Melbourne, VIC 3000, \\ Australia, e-mail: n.das@cqu.edu.au (N.D.) \\ ${ }^{7}$ Centre for Intelligent Systems, School of Engineering and Technology, Central Queensland University, \\ Brisbane, QLD 4000, Australia. \\ * Correspondence: m.nur-e-alam@ecu.edu.au (M.N.-E-A.), and khairulcu@gmail.com (M. K.B.)
}

\begin{abstract}
Zinc-oxide $(\mathrm{ZnO})$ nanostructures including nanorods are currently considered as a pioneer research of interest world-wide due to their excellent application potentials in various applied fields especially for the improvement of energy harvesting photovoltaic solar cells (PSC). We report on the growth and morphological properties of zinc-oxide $(\mathrm{ZnO})$ nanorods grown on the surface of plain zinc (non-etched and chemically etched) plates by using a simple, economical, and environment-friendly technique. We apply hot water treatment (HWT) technique to grow the ZnO nanorods and varies the process parameters, such as temperature and the process time duration. The morphological, and elemental analysis confirm the agglomeration of multiple $\mathrm{ZnO}$ nanorods with its proper stoichiometry. The obtained nanostructures for different temperatures with different time duration showed the variation in uniformity, density, thickness and nanonorods size. The $\mathrm{ZnO}$ nanorods produced on the etched zinc surface were found thicker and uniform as compared to those grown on the non-etched zinc surface. This chemically etched Zinc plates preparation can be an easy solution to grow $\mathrm{ZnO}$ nanorods with high density and uniformity suitable for PSC applications such as to enhance the energy conversion efficiency of the photovoltaic (PV) solar cells towards the future sustainable green earth.
\end{abstract}

Keywords: conversion efficiency; energy harvesting or generation; hot water treatment; nanorods; solar cells; surface etching; surface morphology.

\section{Introduction}

The extraordinary and fine tunable properties (physical and chemical) of nanomaterials suitable for various modern nanotechnology related practical applications is of interest study matter for this century. Many research groups have been dedicated their efforts in the development of various nanomaterials including nanoparticles (polymer, metal, metal-oxide and others of more complex stoichiometry) as well as their optimized synthesis processes. A significant number of reports on the formation and the properties (e.g. electrical, magnetic, magneto-optic, catalytic, mechanical and 
thermal) of different types of nanomaterials are available in literature [1-11] However, the practical applications on specific nanomaterials development is always of importance nowadays due to their potentiality to be used in various emerging and existing applications ranging from medical to security system and energy generation to environmental protection. Among all the nanomaterials, metal-oxide nanostructures are the prime interest of research objectives today. For example, zinc oxide $(\mathrm{ZnO})$ nanostructures including nanowires and nanorods are considered as one of the most advanced nanomaterials research areas due to their application potentials in solar cells, nanogenerators, biosensors and other nanodevices [12-24]. ZnO is itself a semiconductor material of having comparatively wide band gap of approximately $3.3 \mathrm{eV}$ which makes them attractive and alternatives of many other metal-oxides for short-wavelength optoelectronic applications, transparent electronics, transparent energy harvesting devices, and integrated sensors [22, 25-32]. Several reports have also been found in the literature that $\mathrm{ZnO}$ has been used in photoelectrochemical cell (PEC) solar cells development [33-36]. ZnO nanotetrapods could be an example for the near-future developments of solar energy conversion systems to maximize the energy generation to meet up the global energy demands and simultaneously to minimize the environmental issues related to the carbon footprint $[3,9,10,13]$.

There are several conventional fabrication techniques to synthesis $\mathrm{ZnO}$ nanorods such as thermal evaporation, chemical vapor deposition (CVD) and cyclic feeding CVD, sol-gel deposition, electrochemical deposition, hydrothermal and solvo-thermal growth, surfactant and capping agentsassisted [23, 37, 38] However, most of the synthesis methods are expansive, , complicated, nonscalable, environmentally hazardous and required well-trained and experienced operators [39-41] Therefore, it is crucial to have a simple fabrication method that can overcome most of the $\mathrm{ZnO}$ nanorods growth related issues. A simple hot water treatment (HWT) process has been recently demonstrated to produce metal oxide nanostructures on different metal surfaces [41]. In HWT a metal substrate is basically immersing into a hot deionized (DI) water at temperature typically above $75{ }^{\circ} \mathrm{C}$. Therefore, it has the practical features of catalyst-free growth, high-throughput fabrication, and applicability to wide range of materials that have a higher boiling point than water. This HWT growth mechanism mainly follows a dissolution-precipitation process called "plugging" process and surface diffusion. First step for this process is the metal oxide formation (oxidization) and then release of the metal oxide molecule from the surface into the water followed by transportation through water (migration) and the third step is precipitation (re-deposition) of the migrated onto another surface position. The migrated metal-oxide molecules redeposit and stick on the defect sites (voids or grain boundaries with dangling bonds etc.) which are nucleation regions of the surface [41]

Therefore, it is interesting to investigate the effect of surface etching, temperature and time over metallic Zn using hot-water treatment. To our knowledge no further extensive investigation has been conducted to understand these effects on Zn surface. In this work we adopted the basic concepts of HWT to grow the $\mathrm{ZnO}$ nanorods on the etched zinc surface and compared the surface morphology properties with those of non-etched zinc surface.

\section{Materials, Method and Characterization}

Flatten zinc plates ( $99 \%$ in purity) of $2 \mathrm{~mm}$ thickness were purchased from local market and cut these plates into $2 \mathrm{~cm} \times 2 \mathrm{~cm}$ by manual sheet metal cutting machine. The samples were then polished by using a bench polisher grinder machine. The rust and blemishes were removed with flap wheel of 80 grit. Then 120 grit flap wheels were used over $\mathrm{Zn}$ plates to get the desired mirror polished surface. In order to remove the remaining dust particles and residue from the mirror polished surface, the polished $\mathrm{Zn}$ plates were subjected to clean with acetone in an ultrasonic bath for $10 \mathrm{~min}$ followed by cleaning with ultra-pure deionized (DI) water for $10 \mathrm{~min}$. After that some samples were chemically etched using $5 \% \mathrm{HCl}$ in ethanol for $3 \mathrm{~min}$ to observe the effect of etching in $\mathrm{ZnO}$ growth. The reaction happened during etching process can be explain in a simple chemical formula

$$
\mathrm{Zn}+\mathrm{HCl}=\mathrm{H}_{2}+\mathrm{ZnCl}_{2}
$$

It can be noticed that in this single replacement reaction, zinc metal displaces the hydrogen to form hydrogen gas and zinc chloride (salt). Zinc reacts quickly with the hydrochloric acid to form 
bubbles of hydrogen and thus left the $\mathrm{Zn}$ plates with an etched surface. Figure 1 shows the schematic diagram of the $\mathrm{ZnO}$ nanorods growth process sequences and the SEM micrograph for both nonetched and chemically etched Zinc surface, where it can be clearly seen that the oxidation has been occurred and agglomeration of metal-oxide islands are found with the better quality on the chemically etched Zn plate's surface.

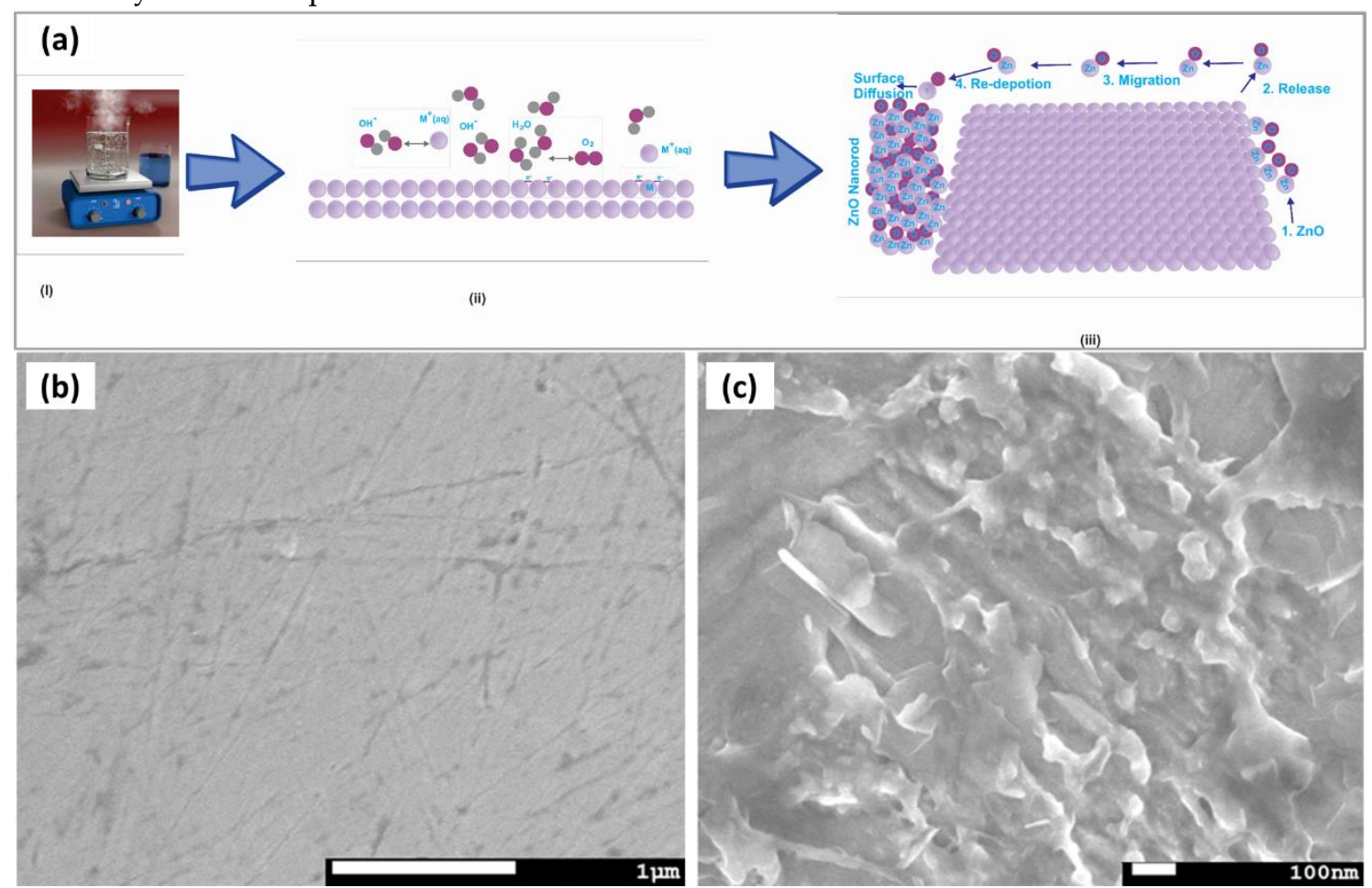

Figure 1: Schematic diagram of the ZnO nanorods growth process (a), SEM micrograph of non-etched (b) and etched (c) Zinc Surface.

In the hot water treatment process a fixed temperature hot plate was used to maintain desirable temperatures, and each sample was emerged in ultrapure DI water at different temperature of $70^{\circ} \mathrm{C}$, $80^{\circ} \mathrm{C}, 90^{\circ} \mathrm{C}$ for different time duration from 10 mins to 60 mins. Based on the results of successful $\mathrm{ZnO}$ nanorods formation on non-etched zinc metal plates, we decided to conduct the HWT process for the etched zinc samples, at a fixed temperature of $80^{\circ} \mathrm{C}$ with a time duration varied from $1-3$ hours. Just after the hot water treatment process, all the samples were dried using nitrogen gas (of purity $99.999 \%$ ) blower at high pressure to remove the least presence of DI water droplets and to stop further oxidation reaction on the zinc surface.. Each of the samples were dispersed on a conducting carbon glued strip and mounted in the main SEM chamber to view its surface.

All the prepared samples were subjected to characterize to investigate their surface morphology and determine the elemental compositional information. The surface morphology of the developed samples were investigated by field emission scanning electron microscope (FESEM, JSM-7600F, JEOL, Japan) to observe the nanostructure of surface. Elemental analysis for the synthesized $\mathrm{ZnO}$ nanorods was performed by energy dispersive X-ray (EDS) diffraction instrument integrated with the FESEM. The sample plates were placed on a conducting carbon glued strip during SEM and EDX analysis to avoid the extra charging on the sample surface.

\section{Results}

The obtained surface morphologies and elemental analysis results are presented into two groups: first we have investigated the microstructural properties of $\mathrm{ZnO}$ nanorods grown onto nonetched Zn surface after the hot water treatment performed at $70^{\circ} \mathrm{C}, 80^{\circ} \mathrm{C} \& 90^{\circ} \mathrm{C}$ for $10 \mathrm{~min}, 20 \mathrm{~min}$, $30 \mathrm{~min} 45 \mathrm{~min}$ and $60 \mathrm{~min}$. Secondly we have presented the surface morphologies and compositional elements of $\mathrm{ZnO}$ nanrods grown onto the chemically etched $\mathrm{Zn}$ plates after hot water treatment conducted at $80^{\circ} \mathrm{C}$ for three different $(1 \mathrm{hr}, 2 \mathrm{hr}$ and $3 \mathrm{hr})$ process time duration. 


\subsection{SEM analysis of $\mathrm{ZnO}$ nanorods formation at different temperature on non-etched surface}

\subsubsection{Hot water treatment conducted at $70{ }^{\circ} \mathrm{C}$}

Figure 2 represents the top view of the zinc surfaces which were subjected to HWT at $70^{\circ} \mathrm{C}$ for five different process time duration of $10 \mathrm{~min}, 20 \mathrm{~min}, 30 \mathrm{~min}, 45 \mathrm{~min}$ and $60 \mathrm{~min}$. Figure 2(a-e) shows the SEM micrographs for zinc surfaces at $1 \mu \mathrm{m}$ depth resolution with $\times 20,000$ magnification while figure 2 (f-j) represents the SEM micrographs of zinc surfaces at $100 \mathrm{~nm}$ depth resolution with $x$ 100,000 magnification range. It can be clearly seen that the nanostructure formation at the process of $70^{\circ} \mathrm{C}, 10 \mathrm{~min}$ HWT treatment, was just about to grow but its density was not enough as compared to others time variation as depicted in the figure. The HWT treatment at $70^{\circ} \mathrm{C}$ for $20 \mathrm{~min}$ shows better growth than 10 min one. Nanowire type formation was noted at the surface of the zinc metal. At longer treatment time, interestingly we observed the mixture of nanowires and nanorods formation at the surface. The obtained SEM micrographs confirm the mixture of the nanowire and nanorods type formation at $30 \mathrm{~min}, 45 \mathrm{~min}$ and $60 \mathrm{~min}$ of HWT. At longer time nanowires has shown to transform into nanorods. The HWT treatment at $70^{\circ} \mathrm{C}$ for 45 min showed better nanorods formation than any other time duration at $70^{\circ} \mathrm{C}$. However, the HWT treatment at $70^{\circ} \mathrm{C}$ provided a slow growth rate.

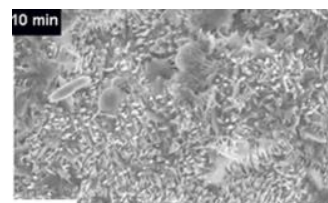

(a)

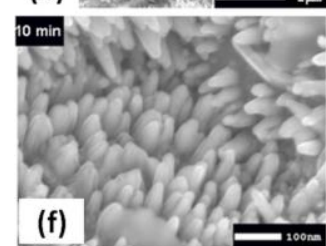

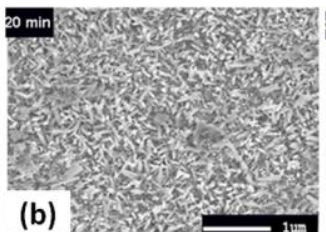

(b)

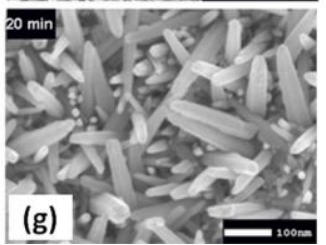

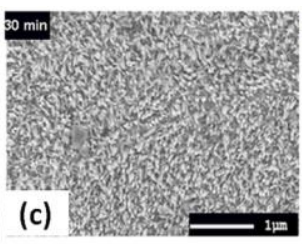

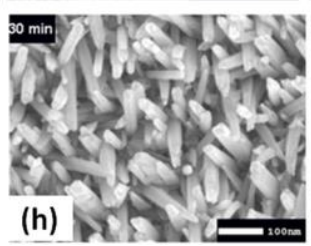

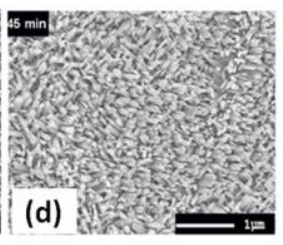
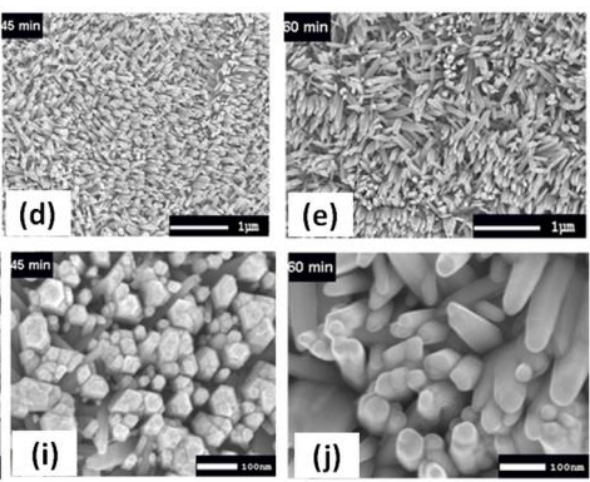

Figure 2: Top-view SEM micrographs of $\mathrm{ZnO}$ nanostructures formed after the $70^{\circ} \mathrm{C}$ hot water treatment process: (a-e) $1 \mu \mathrm{m}$ depth resolution $\times 20,000$ magnification and (f-j) $100 \mathrm{~nm}$ depth resolution $\times 100,000$ magnification gives a closer view of the nanostructure formation.

\subsubsection{Hot water treatment conducted at $80^{\circ} \mathrm{C}$}

Figure 3 shows the SEM micrographs $\mathrm{ZnO}$ nanostructures formed onto non-etched $\mathrm{Zn}$ metal surfaces after the HWT water treatment process, conducted at $80^{\circ} \mathrm{C}$. The surface of the zinc metal sheets were found to be covered with $\mathrm{ZnO}$ nanostructures and the surface was not visible anymore. The length of the structures were observed minimal though, however as compared to those obtained after hot water treatment at $70^{\circ} \mathrm{C}$ the structural development of $\mathrm{ZnO}$ was found to exhibit better growth. It was observed that the grain size of the $\mathrm{ZnO}$ nanostructures (after the process run for 10 mins) were not equal in size and the growth density was not dense enough. With the increase of time duration, the size uniformity and growth rate was found to be increased. The HWT treatment for $20 \mathrm{~min}$ shows better nanostructure formation than that of $10 \mathrm{~min}$. The HWT treatment for $30 \mathrm{~min}$ shows the uniformity in size of the developed nanowires and at this temperature few nanorods are also formed. 45 min treatment shows better amount of nanorods than 30 min treatment. The HWT treatment at $80^{\circ} \mathrm{C}$ for $45 \mathrm{~min}$ the nanowires are transformed to nanorods and shows well uniformity in size of the nanoroads. 45 min treatment gives more thick nanorods than reducing the duration of treatment. The HWT at $80^{\circ} \mathrm{C}$ for 60 min shows better growth than any other time duration. Growth rate is also high for $60 \mathrm{~min}$ but the directional growth shows less uniformity. The directional growth was found non-uniform though it has uniformity in certain domains. This temperature provided slow growth but comparatively better than $70^{\circ} \mathrm{C}$. 

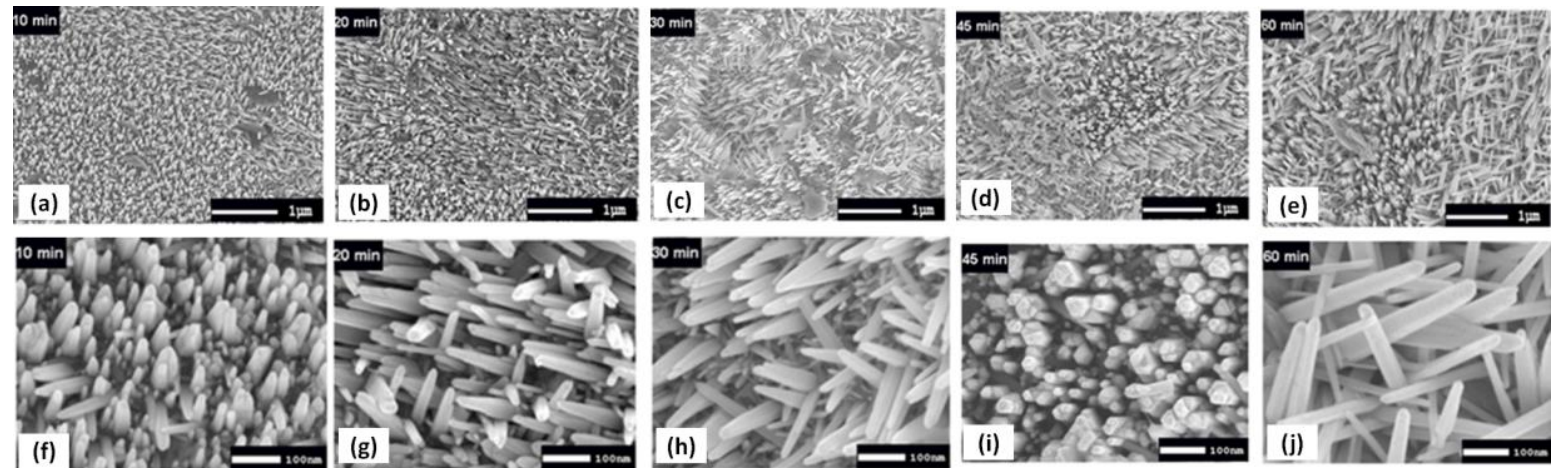

Figure 3: Top-view SEM micrographs of $\mathrm{ZnO}$ nanostructures formed after the $80^{\circ} \mathrm{C}$ hot water treatment process: (a-e) $1 \mu \mathrm{m}$ depth resolution x 20,000 magnification and (f-j) $100 \mathrm{~nm}$ depth resolution $\times 100,000$ magnification.

\subsubsection{Hot water treatment conducted at $90^{\circ} \mathrm{C}$}

Figure. 4 shows the SEM micrographs of $\mathrm{ZnO}$ nanostructures formed after the HWT treatment conducted at $90^{\circ} \mathrm{C}$ with the variation of time duration. Treatment for 10 min shows better and thick growth of nanostructures at the surface compared to 10 min growth observed in Figs. 2 and 3. At 10 min a mixture of nanowires and nanorods are started to develop at a higher growth rate than the temperature explained before. As time increases, at $90^{\circ} \mathrm{C}$ the length of the $\mathrm{ZnO}$ nanorods were found increased. In Figure. 4 (f-j), 20 min treatment shows the non-uniform growth in direction and size. However, 30 min treatment shows better uniformity in directional growth only and 45 min treatment shows better growth both in uniform density and size than that observed any other micrographs as shown in Fig. 4, but the thickness of every nanorods or nanowires were found unequal. However, 60 min treatment shows more densely nanostructure on the surface than any other treatment in this study. But in this HWT treatment at $90^{\circ} \mathrm{C}$ for $60 \mathrm{~min}$, the developed nano-ZnO layer is also thick enough compared to other micrographs in this study. HWT treatment at $90^{\circ} \mathrm{C}$ gives better growth rate than that obtained at $70^{\circ} \mathrm{C}$ or $80^{\circ} \mathrm{C}$.
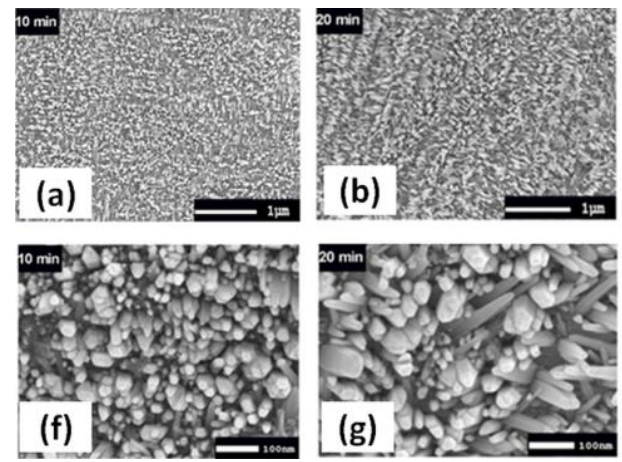
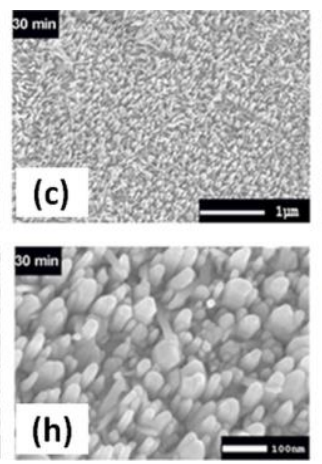
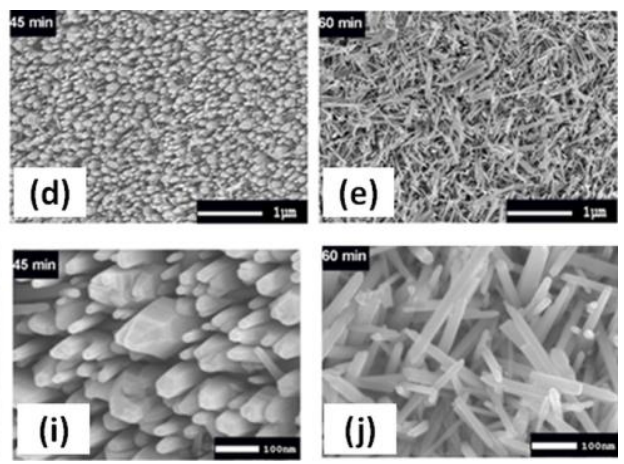

Figure 4: Top-view SEM micrographs of $\mathrm{ZnO}$ nanostructures formed after the $90^{\circ} \mathrm{C}$ hot water treatment process: (a-e) $1 \mu \mathrm{m}$ depth resolution x 20,000 magnification and (f-j) $100 \mathrm{~nm}$ depth resolution $\times$ 100,000 magnification.

\subsection{EDX analysis of nanorods formation at different temperature on non-etched surface}

The semi-quantitative analysis of the $\mathrm{ZnO}$ nanostructures were carried out by $\mathrm{EDX}$. Two strong peaks corresponding to $\mathrm{L}$ shell of zinc and $\mathrm{K}$ shell of oxygen were found in the spectrum confirming formation of $\mathrm{ZnO}$ nanostructures with high purity. At high operating voltage the electron beam penetrates nanostructure and reaches the inner zinc plate, which results in a little higher percentage of $\mathrm{Zn}$ atoms than oxygen. The observed EDX results closedly agreed with the similar results explained in Refs[42-45]. The EDX spectrum for HWT at $70^{\circ} \mathrm{C}, 80^{\circ} \mathrm{C}$ and $90^{\circ} \mathrm{C}$ for $45 \mathrm{~min}$ each are shown in the Fig. 5. The bar diagram shown in Fig. $5 \mathrm{~d}$ depicts $\mathrm{Zn}$ and $\mathrm{O}$ atom percentage. The atomic ratio of zinc and oxygen $(\mathrm{Zn}: \mathrm{O})$ found from EDX data are 1.05 for $70^{\circ} \mathrm{C}, 1.27$ for $80^{\circ} \mathrm{C}$ and 1.07 for $90^{\circ} \mathrm{C}$. EDX spectrum for each temperature shows little impurity which are red covered area in the spectrum. The oxygen atoms $\%$ is little higher for $70^{\circ} \mathrm{C}$ compared to others. $80^{\circ} \mathrm{C}$ shows higher $\mathrm{Zn}$ 
atom \% because electron beam cover little higher area of the zinc surface than others i.e, we can say for $80{ }^{\circ} \mathrm{C}$, the HWT treated surface gives more space to penetrate the electron beam than $70^{\circ} \mathrm{C}$ or $80^{\circ} \mathrm{C}$ does.
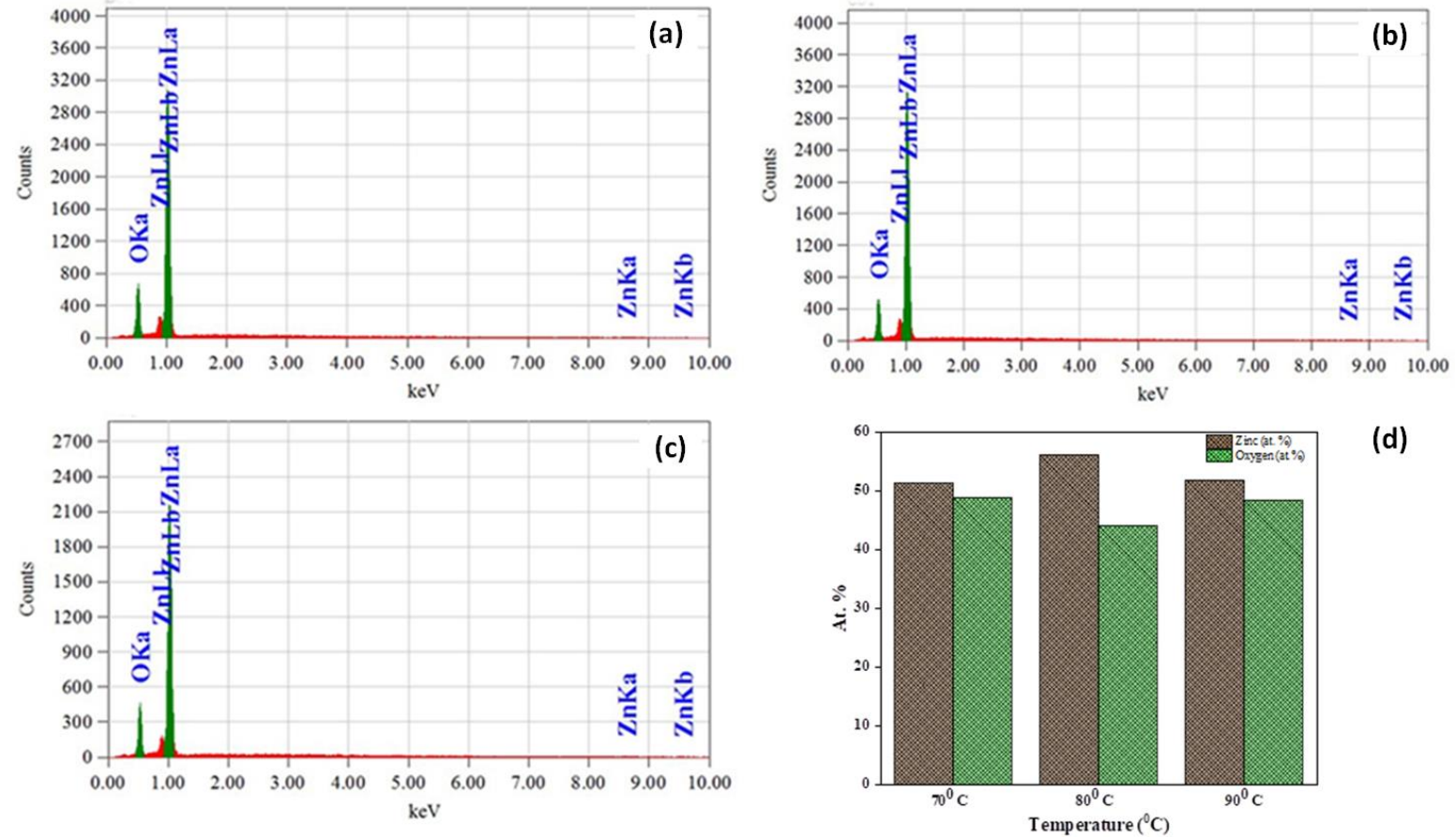

(d)

Figure 5: EDX patterns for compositional analysis. (a) EDX pattern for $\mathrm{HWT}$ at $70^{\circ} \mathrm{C}$ for $45 \mathrm{~min}$ time duration, (b) EDX pattern for $\mathrm{HWT}$ at $80^{\circ} \mathrm{C}$ for $45 \mathrm{~min}$ time duration, (c) EDX pattern for $\mathrm{HWT}$ at $90^{\circ} \mathrm{C}$ for $45 \mathrm{~min}$ time duration, and (d) $\mathrm{Zn}$ and $\mathrm{O}$ atom percentage found from EDX spectrum.

\subsection{SEM analysis of $\mathrm{ZnO}$ nanorods formed on chemically etched surface}

Figure. 6 shows SEM micrographs for etched surfaces of zinc subjected to HWT for 1-3 hr at $80^{\circ} \mathrm{C}$. It is clearly seen that etched zinc surface produces nanorods with higher diameter than the nonetched surface. A well base structure formation is noticed in the etched surface, it has no uniform base structure in the surface without etching. However, this disparity was overcome by increasing time. Figure 6 (d-f) shows a clear picture of the formed nanorods and the top surfaces of the nanorods show hexagonal structure of the nanorods. For $2 \mathrm{hr}$ the grown nanorods are more thick than $1 \mathrm{hr}$ or 3 hr.
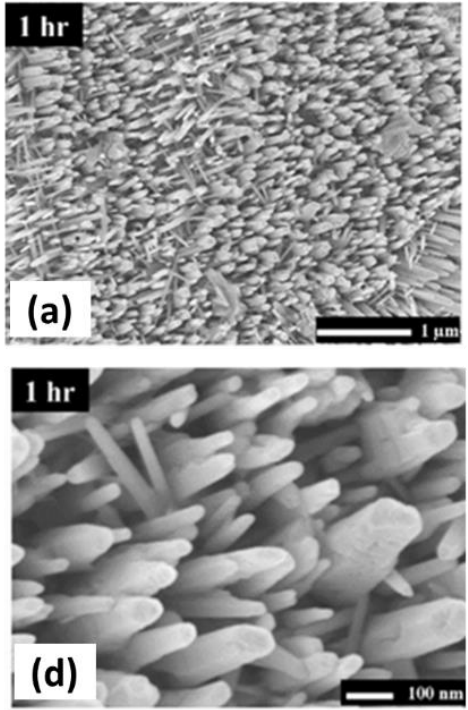
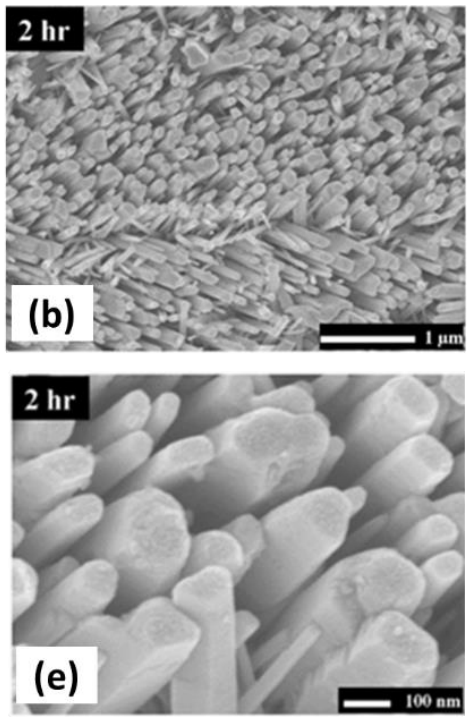
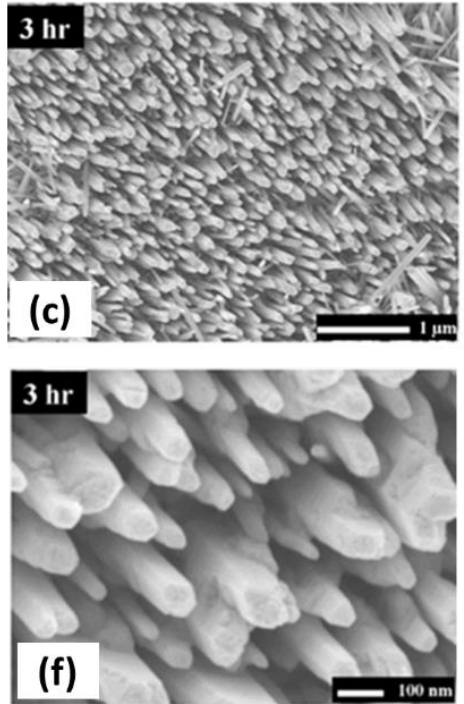
Figure 6: Top-view SEM micrographs of $\mathrm{ZnO}$ nanostructures formed onto etched surface at $80^{\circ} \mathrm{C}$ hot water treatment process: (a-c) $1 \mu \mathrm{m}$ depth resolution $\times$ 20,000 magnification and (d-f) $100 \mathrm{~nm}$ depth resolution $\times 100,000$ magnification.

Comparing with the previous studies of SEM morphological analysis it is clear from Figs. 2, 4, $4 \& 6$ that $\mathrm{ZnO}$ nanostructure was correctly formed. From SEM micrographs of Figs. $2-4$ it is seen that temperature has a significant effect on the growth and uniformity of the $\mathrm{ZnO}$ nanostructure produced by hot water treatment. With higher temperature we achieved the fast growth and faster agglomeration, more thick structures though it has lost substantial amount of uniformity achieved with lower temperate.

\subsection{EDX analysis of $\mathrm{ZnO}$ nanorods formed on chemically etched surface}

The elemental composition of nanorods formed on the etched zinc surface is determined by EDX. The EDX spectrum for HWT at $80^{\circ} \mathrm{C}$ for $1 \mathrm{hr}, 2 \mathrm{hr}$ and $3 \mathrm{hr}$ are shown in the Fig. 7. The bar diagram shown in Fig. $7 \mathrm{~d}$ shows $\mathrm{Zn}$ and $\mathrm{O}$ atom percentage. The atomic ratio of zinc and oxygen $(\mathrm{Zn}: \mathrm{O})$ found from EDX data are 1.04 for $1 \mathrm{hr}, 1.13$ for $2 \mathrm{hr}$ and 1.12 for $3 \mathrm{hr}$ where the average oxygen atoms $\%$ is 1.10. EDX spectrum for each time duration show little impurity which are red covered area in the spectrum similar to the observed EDX spectra presented in section 3.2. It is clearly seen that there is no significant effect of temperature, time and etching on the elemental variation of $\mathrm{ZnO}$ nanorods.
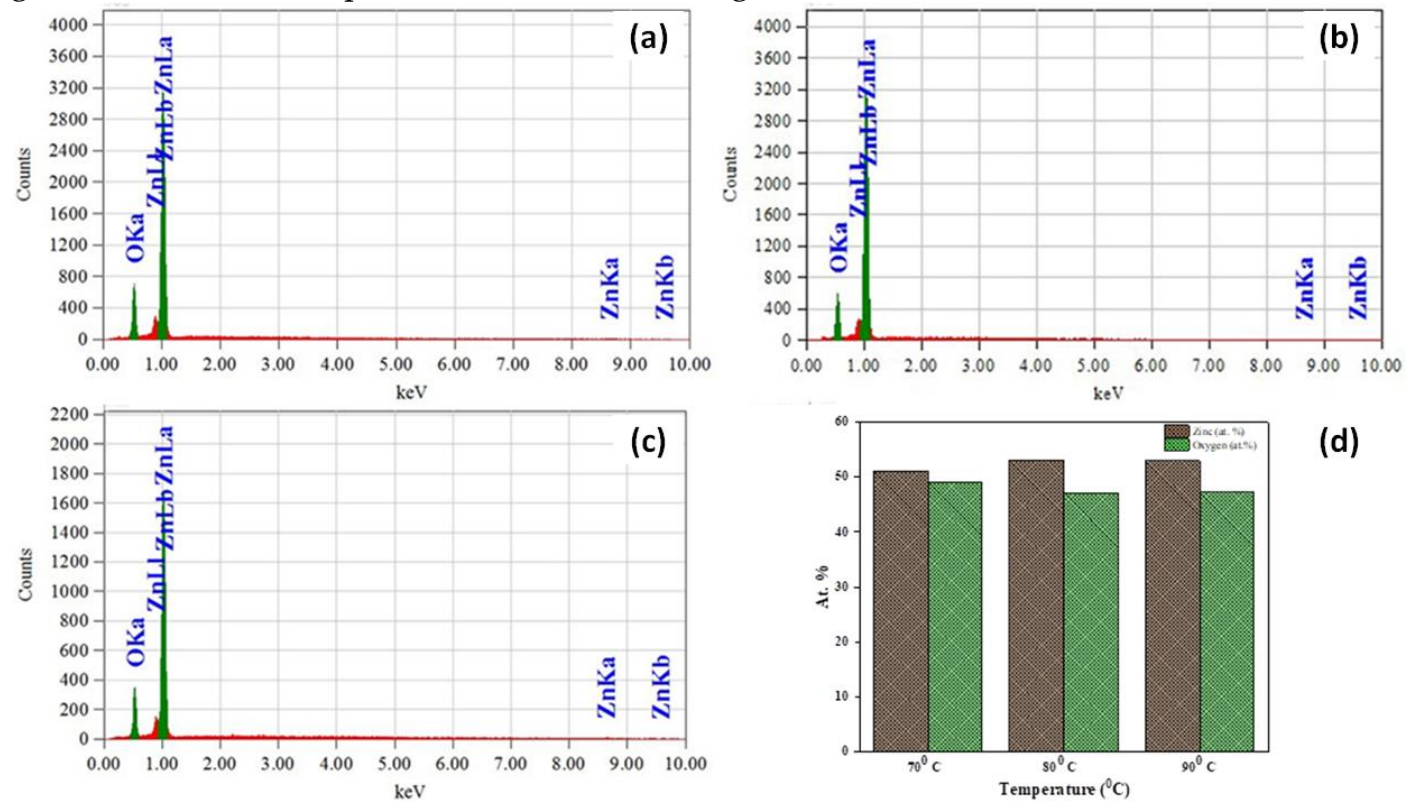

(d)

Figure 7: EDX patterns for etched Zn surface after HWT at $80^{\circ} \mathrm{C}$ for $1 \mathrm{hr}, 2 \mathrm{hr} \& 3 \mathrm{hr}$ time duration. (a) EDX pattern for $1 \mathrm{hr}$, (b) EDX pattern for $2 \mathrm{hr}$, (c) EDX pattern for 3hr, and (d) Zn and O atom percentage found from EDX spectrum for etched Zn surface after HWT.

Plugging process is more dominant for etched $\mathrm{Zn}$ surface as compared to non-etched $\mathrm{Zn}$ surface. The etched surface more rough and there is more defect sites than the etched surface. At temperature $70^{\circ} \mathrm{C}$ the growth of $\mathrm{ZnO}$ nanostructure (shown in Fig. 2) was slower than other but showed more uniform growth compared to nanostructure produced at the higher temperatures. Eventually $80^{\circ} \mathrm{C}$ gives an average outcome shown in Fig. 4 both in growth rate and structural uniformity. With well enough etching it might be possible for hot water treatment at $80^{\circ} \mathrm{C}$ to achieve the structural growth rate similar to $90^{\circ} \mathrm{C}$ as shown in Fig. $5 \mathrm{~d}$. Figures $2,4 \& 5 \mathrm{~d}$ evidently show the relation between time and length of $\mathrm{ZnO}$ nanostructure growth by hot water treatment. From the experimental results it is clear that time has direct relationship with the length of the nanostructures. The higher HWT time corresponds to higher structural length even in the non-etched surfaces. So, time is the key factor for achieving required height of $\mathrm{ZnO}$ nanostructures along with the temperature. The temperature does not have direct relation with height as time have but the thick base which is resulted from high 
temperature might be a factor as time. It seems that chemical etching of plain $\mathrm{Zn}$ metal sheets might be a solution for better growth $\mathrm{ZnO}$ nanorods with adequate thickness uniformity.

\section{Conclusions}

In summary, a comparative study relating to etching, temperature and time for hot water treatment for $\mathrm{ZnO}$ nanorods formation have been demonstrated in detail which can be applicable to potentially enhance the conversion efficiency of solar photovoltaic (PV) cells. The obtained surface morphology properties confirm the successful growth and formation of $\mathrm{ZnO}$ nanorods. Effects of time on the nanostructure growth rate and thickness of different zinc surfaces have also been extensively studied. This study successfully achieved the control over population, size, thickness, and uniformity of $\mathrm{ZnO}$ nanorods. These results have significant impact on the $\mathrm{ZnO}$ assisted solar PV technology where uniformity and thickness of nanorods that are necessary to manufacture in future high efficient solar or PV cells for a sustainable green earth.

Author Contributions: Conceptualization, M. K. B. and S. M. S. R..; methodology, S. M. S. R.; formal analysis, S. M. S. R.; investigation, M. K. B. and M. A. M..; writing-original draft preparation, M. H. and M. K. B..; writingreview and editing, M. K. H., and M. N.-E-A..; visualization, M. A. R. A. and S. M. A. Al-Z..; consulting, M. K. H., N. D. and M. N.-E-A.; supervision, M. N.-E-A. All authors have read and agreed to the published version of the manuscript.

Funding: This research received no external funding.

Acknowledgments: The authors would like to acknowledge the department of Glass and Ceramic Engineering, Bangladesh University of Engineering and Technology (BUET), and the Institute of Electronics of Bangladesh Atomic Energy Commission for their numerous support for this research work.

Conflicts of Interest: The authors declare no conflict of interest.

\section{References}

1. Zhang, R.-Q.; Lifshitz, Y.; Lee, S.-T. Oxide-assisted growth of semiconducting nanowires. Advanced Materials 2003, 15, 635-640, doi:10.1002/adma.200301641.

2. Mårtensson, T.; Borgström, M.; Seifert, W.; Ohlsson, B.J.; Samuelson, L. Fabrication of individually seeded nanowire arrays by vapour-liquid-solid growth. Nanotechnology 2003, 14, 1255-1258, doi:10.1088/0957-4484/14/12/004.

3. Kumar, S.; Baruah, S.; Puzari, A. Poly(p-phenylenediamine)-based nanocomposites with metal oxide nanoparticle for optoelectronic and magneto-optic application. Polymer Bulletin 2020, 77, 441-457, doi:10.1007/s00289-019-02760-9.

4. Zhang, Y.; Ram, M.K.; Stefanakos, E.K.; Goswami, D.Y. Synthesis, Characterization, and Applications of $\mathrm{ZnO}$ Nanowires. Journal of Nanomaterials 2012, 2012, 1-22, doi:10.1155/2012/624520.

5. Cai, Z.; Liu, B.; Zou, X.; Cheng, H.-M. Chemical Vapor Deposition Growth and Applications of Two-Dimensional Materials and Their Heterostructures. Chemical Reviews 2018, 118, 6091-6133, doi:10.1021/acs.chemrev.7b00536.

6. Chakraborty, S.; Mandal, S.K.; Saha, B. Magneto-optic and magneto-electric effects in poly(vinylidene fluoride) - $\mathrm{Zn} 0.2 \mathrm{Co} 0.8 \mathrm{Fe} 2 \mathrm{O} 4$ nanocomposite organic flexible film. Ceramics International 2019, 45, 14851-14858, doi:10.1016/j.ceramint.2019.04.216.

7. Li, S.; Meng Lin, M.; Toprak, M.S.; Kim, D.K.; Muhammed, M. Nanocomposites of polymer and inorganic nanoparticles for optical and magnetic applications. Nano Reviews 2010, 1 , 5214, doi:10.3402/nano.v1i0.5214. 
8. Gatelytè, A.; Jasaitis, D.; Beganskienè, A.; Kareiva, A. Sol-Gel Synthesis and Characterization of Selected Transition Metal Nano-Ferrites. Materials Science 2011, 17, doi:10.5755/j01.ms.17.3.598.

9. Rashad, M.M.; Mohamed, R.M.; Ibrahim, M.A.; Ismail, L.F.M.; Abdel-Aal, E.A. Magnetic and catalytic properties of cubic copper ferrite nanopowders synthesized from secondary resources. Advanced Powder Technology 2012, 23, 315-323, doi:10.1016/j.apt.2011.04.005.

10. Vayssieres, L. On the design of advanced metal oxide nanomaterials. International Journal of Nanotechnology 2004, 1, 1, doi:10.1504/IJNT.2004.003728.

11. Wu, F.; Hu, W.P. Nano Materials Used in Industrial Design. Advanced Materials Research 2011, 415-417, 545-548, doi:10.4028/www.scientific.net/AMR.415-417.545.

12. Bramantyo, A.; Murakami, K.; Okuya, M.; Udhiarto, A.; Poespawati N. R. Growth of Zinc Oxide Nanorods with the Thickness of Less than or Equal to $1 \mu \mathrm{m}$ through Zinc Acetate or Zinc Nitrate for Perovskite Solar Cell Applications. Journal of Engineering. 2019, 2793853, https://doi.org/10.1155/2019/2793853

13. Leschkies, K.S.; Divakar, R.; Basu, J.; Enache-Pommer, E.; Boercker, J.E.; Carter, C.B.; Kortshagen, U.R.; Norris, D.J.; Aydil, E.S. Photosensitization of ZnO Nanowires with CdSe Quantum Dots for Photovoltaic Devices. Nano Letters 2007, 7, 1793-1798, doi:10.1021/n1070430o.

14. Ozu, S.; Zhang, Y.; Yasuda, H.; Kitabatake, Y.; Toyoda, T.; Hirata, M.; Yoshino, K.; Katayama, K.; Hayase, S.; Wang, R.; et al. Improving Photovoltaic Performance of ZnO Nanowires Based Colloidal Quantum Dot Solar Cells via SnO2 Passivation Strategy. Frontiers in Energy Research 2019, 7, doi:10.3389/fenrg.2019.00011.

15. Arya, S.K.; Saha, S.; Ramirez-Vick, J.E.; Gupta, V.; Bhansali, S.; Singh, S.P. Recent advances in $\mathrm{ZnO}$ nanostructures and thin films for biosensor applications: Review. Analytica Chimica Acta 2012, 737, 1-21, doi:10.1016/j.aca.2012.05.048.

16. Deepika, S.; Kumar, R.H.; Selvaraj, C.I.; Roopan, S.M. Toxicity of metal/metal oxide nanoparticles and their future prospects. In The Macabresque: Human Violation and Hate in Genocide, Mass Atrocity and Enemy-Making; John Wiley \& Sons, Inc.: Hoboken, NJ, USA, 2018; pp. 141-164 ISBN 9781119418900.

17. Cheng, J.J.; Chuang, C.-H.M.; Hentz, O.; Rekemeyer, P.H.; Bawendi, M.G.; Gradečak, S. Dimension- and Surface-Tailored ZnO Nanowires Enhance Charge Collection in Quantum Dot Photovoltaic Devices. ACS Applied Energy Materials 2018, 1, 1815-1822, doi:10.1021/acsaem.8b00204.

18. Wahab, R.; Hwang, I.H.; Shin, H.-S.; Kim, Y.-S.; Musarrat, J.; Al-Khedhairy, A.A.; Siddiqui, M.A. Zinc Oxide Nanostructures and their Applications. In Intelligent Nanomaterialsle; John Wiley \& Sons, Inc.: Hoboken, 2012; ISBN 9780470938799.

19. Fan, J.C.; Chang, S.L.; Xie, Z. ZnO-Based Light-Emitting Diodes. In Optoelectronics Advanced Materials and Devices; InTech, 2013.

20. Wang, Z.L. Piezoelectric Nanogenerators Based on Zinc Oxide Nanowire Arrays. Science 2006, 312, 242-246, doi:10.1126/science.1124005. 
21. Wang, X.; Zhou, J.; Wang, Z.L. Nanopiezotronics and nanogenerators. In Microsystems and Nanotechnology; Springer-Verlag Berlin Heidelberg, 2012; Vol. 9783642182, pp. 115-147 ISBN 9783642182938.

22. Chen, W.; Qiu, Y.; Yang, S. Branched $\mathrm{ZnO}$ nanostructures as building blocks of photoelectrodes for efficient solar energy conversion. Physical Chemistry Chemical Physics 2012, 14, 10872, doi:10.1039/c2cp41272a.

23. Gogotsi, Y. Designing Carbon Crystals for Nanotechnology Applications. Crystal Growth \& Design 2001, 1, 179-181, doi:10.1021/cg015501q.

24. Look, D.C. Recent advances in $\mathrm{ZnO}$ materials and devices. Materials Science and Engineering: B 2001, 80, 383-387, doi:10.1016/S0921-5107(00)00604-8.

25. Raghavender, A.T.; Varma, M.C.; Deb, S.; Hong, N.H. Tuning the band-gap of zinc oxide by first principle studies. In Proceedings of the AIP Conference Proceedings; American Institute of Physics Inc., 2017; Vol. 1832, p. 120012.

26. Srikant, V.; Clarke, D.R. On the optical band gap of zinc oxide. Journal of Applied Physics 1998, 83, 5447-5451, doi:10.1063/1.367375.

27. Djurišić, A.B.; Ng, A.M.C.; Chen, X.Y. ZnO nanostructures for optoelectronics: Material properties and device applications. Progress in Quantum Electronics 2010, 34, 191-259, doi:10.1016/j.pquantelec.2010.04.001.

28. Özgür, Ü.; Alivov, Y.I.; Liu, C.; Teke, A.; Reshchikov, M.A.; Doğan, S.; Avrutin, V.; Cho, S.J.; Morkoç, H. A comprehensive review of $\mathrm{ZnO}$ materials and devices. Journal of Applied Physics 2005, 98, 041301, doi:10.1063/1.1992666.

29. Klingshirn, C. ZnO: Material, Physics and Applications. ChemPhysChem 2007, 8, 782-803, doi:10.1002/cphc.200700002.

30. Aranovich, J.; Ortiz, A.; Bube, R.H. Optical and electrical properties of $\mathrm{ZnO}$ films prepared by spray pyrolysis for solar cell applications. Journal of Vacuum Science and Technology 1979, 16, 994-1003, doi:10.1116/1.570167.

31. Lee, J.-H.; Ko, K.-H.; Park, B.-O. Electrical and optical properties of $\mathrm{ZnO}$ transparent conducting films by the sol-gel method. Journal of Crystal Growth 2003, 247, 119-125, doi:10.1016/S0022-0248(02)01907-3.

32. Cha, S.N.; Jang, J.E.; Choi, Y.; Amaratunga, G.A.J.; Ho, G.W.; Welland, M.E.; Hasko, D.G.; Kang, D.-J.; Kim, J.M. High performance $\mathrm{ZnO}$ nanowire field effect transistor using selfaligned nanogap gate electrodes. Applied Physics Letters 2006, 89, 263102, doi:10.1063/1.2416249.

33. Roza, L.; Rahman, M.Y.A.; Umar, A.A.; Salleh, M.M. Direct growth of oriented ZnO nanotubes by self-selective etching at lower temperature for photo-electrochemical (PEC) solar cell application. Journal of Alloys and Compounds 2015, 618, 153-158, doi:10.1016/j.jallcom.2014.08.113.

34. Suresh, P.; Sharma, S.K.; Roy, M.S.; Sharma, G.D. Photocurrent mechanism and photovoltaic properties of photo-electrochemical device based on PPAT and PPAT:TY blend. Synthetic Metals 2009, 159, 52-61, doi:10.1016/j.synthmet.2008.07.022. 
35. Ym, H. Photoelectrocatalytic degradation of methylene blue using spray deposited Zno thin films under uv illumination. MOJ Polymer Science 2017, 1, doi:10.15406/mojps.2017.01.00020.

36. Hernández Battez, A.; González, R.; Viesca, J.L.; Fernández, J.E.; Díaz Fernández, J.M.; Machado, A.; Chou, R.; Riba, J. CuO, $\mathrm{ZrO} 2$ and $\mathrm{ZnO}$ nanoparticles as antiwear additive in oil lubricants. Wear 2008, 265, 422-428, doi:10.1016/j.wear.2007.11.013.

37. Kamardin, I.L.K.; Ainuddin, A.R. Studies on Effect of Zinc Oxide (ZnO) Nanostructures Morphology by Modification of Sol-Gel Solution. Advanced Materials Research 2015, 1125, 106-110, doi:10.4028/www.scientific.net/AMR.1125.106.

38. Kamardin, I.L.K.; Ainuddin, A.R. Growth of $\mathrm{ZnO}$ on Flexible Substrate via Sol-Gel Hot Water Treatment. Materials Science Forum 2017, 888, 338-343, doi:10.4028/www.scientific.net/MSF.888.338.

39. Saadi, N.S.; Hassan, L.B.; Brozak, M.; Karabacak, T. Special wettable nanostructured copper mesh achieved by a facile hot water treatment process. Materials Research Express 2017, 4, 095021, doi:10.1088/2053-1591/aa8752.

40. Khedir, K.R.; Saifaldeen, Z.S.; Demirkan, T.; Abdulrahman, R.B.; Karabacak, T. Growth of Zinc Oxide Nanorod and Nanoflower Structures by Facile Treatment of Zinc Thin Films in Boiling De-Ionized Water. Journal of Nanoscience and Nanotechnology 2017, 17, 4842-4850, doi:10.1166/jnn.2017.13432.

41. Saadi, N.S.; Hassan, L.B.; Karabacak, T. Metal oxide nanostructures by a simple hot water treatment. Scientific Reports 2017, 7, 7158, doi:10.1038/s41598-017-07783-8.

42. Bindu, P.; Thomas, S. Estimation of lattice strain in $\mathrm{ZnO}$ nanoparticles: $\mathrm{X}$-ray peak profile analysis. Journal of Theoretical and Applied Physics 2014, 8, 123-134, doi:10.1007/s40094-0140141-9.

43. Ridhuan, N.S.; Abdul Razak, K.; Lockman, Z.; Abdul Aziz, A. Structural and Morphology of $\mathrm{ZnO}$ Nanorods Synthesized Using ZnO Seeded Growth Hydrothermal Method and Its Properties as UV Sensing. PLoS ONE 2012, 7, e50405, doi:10.1371/journal.pone.0050405.

44. Ungár, T.; Gubicza, J. Nanocrystalline materials studied by powder diffraction line profile analysis. Zeitschrift für Kristallographie - Crystalline Materials 2007, 222, doi:10.1524/zkri.2007.222.3-4.114.

45. Kärber, E.; Raadik, T.; Dedova, T.; Krustok, J.; Mere, A.; Mikli, V.; Krunks, M. Photoluminescence of spray pyrolysis deposited $\mathrm{ZnO}$ nanorods. Nanoscale Research Letters 2011, 6, 359, doi:10.1186/1556-276X-6-359. 